\title{
Sampling and Quantitative Analysis of Smoke during a Fire Spreading Through a Mediterranean Scrub
}

\author{
TOUSSAINT BARBONI, ERIC LEONI, DOMINIQUE CANCELLIERI, \\ XAVIER SILVANI, NATHALIE CHIARAMONTI, and PAUL ANTOINE SANTONI \\ UMR CNRS 6134 \\ University of Corsica \\ Quartier Grossetti \\ 20250 CORTE, France
}

\begin{abstract}
This work consists in sampling and analyzing volatiles and smoke released by a typical Mediterranean vegetation during a fire. On an experimental burning plot, we used two original devices to collect volatiles and smoke. Thanks to air sampling pumps, atmosphere samples were taken, into cartridges filled with an adsorbent and into tedlar bags. The test site was instrumented with different other sensors (thermocouples, fluxmeters, anemometers, IR and visible cameras) in order to get the maximum data [1]. Analyses were performed at the laboratory by gas chromatography one day after the field experiment. Samples were thermally desorbed from the cartridges in the GC column coupled to a MS detector. We aim to characterize the risks related to the toxicity of smoke in actual conditions. Benzene, Toluene and Xylene (BTX) are highly toxic compounds that we propose to quantify in the smoke sampled during the fire. Quantification of such compounds was done with an external calibration using commercial mixtures of BTX.
\end{abstract}

KEYWORDS: wildfires, toxicity, smoke, risk assessment, vegetation

\section{INTRODUCTION}

Each year, thousands of hectares of forest burn in Europe and more precisely in the Mediterranean basin. The proximate analysis shows that a plant is composed of organic matter made up of carbon: $51 \%$, hydrogen: $6 \%$ and oxygen: $43 \%$ on a dry basis. These elements are combined to form the principal components which are: cellulose (40 to $45 \%$ for coniferous trees and 38 to 50\% for leafy trees), lignin (26 to 34\% for coniferous trees and 23 to $30 \%$ for leafy trees), hemicellulose (7 to 15\% for coniferous trees and 19 to $26 \%$ for leafy trees), extractives $(<4 \%)$ and ashes $(<1 \%)$ [2,3]. Subjected to an external heat flux such as a flame, volatile compounds (terpenes, tannins or ketones) are emitted from fuels. These compounds are released before the pyrolysis i.e., without degradation of the plant between ambient temperature and $200^{\circ} \mathrm{C}$. At higher temperatures the principal components start to degrade, hemicellulose leads to the formation of volatiles and gas (carbon monoxide and carbon dioxide), the decomposition of cellulose involves the formation of low-weight hydrocarbons (methane, ethane, ethylene...), finally the decomposition of lignin leads to a high quantity of char (50 to 55\%). In addition secondary reactions occur, increasing the diversity of products obtained (reactions and recombinations of products by polymerization, dehydratation or cracking) [4]. Studies on the decomposition of cellulose, hemicellulose and lignin were undertaken and indicate the formation of more than 100 compounds derived from polysaccharides [5] for holocellulose and 80 compounds (in particular hydrocarbons and phenols) for lignin [6]. All these molecules take part in the combustion and the propagation of fire. Several 
compounds are expected in the vapor phase surrounding the vegetation in the smoke near the fire. Smoke is composed by fine dangerous particles lower than $0.1 \mu \mathrm{m}$ in diameter, that penetrate in the body by the respiratory tracts (mouth or nose) crossing the higher respiratory tracts until the lungs. In the air cells particles are in contact with the blood capillaries where the vital exchange (transport of oxygen in blood) is done. Indeed the smoke particles being fine, they are not stopped by the higher respiratory tracts, and thus increase the toxic capacity of these molecules.

Working at actual scale is our aim, so we set up two gases sampling devices on the experimental field. Identifying and quantifying the products emitted by natural fuels in actual conditions is a hard task. We used this experimental burning plot in collaboration with physicians who followed wind velocity, radiant heat flux, temperature distribution during the propagation. The knowledge of gases emitted by the thermal degradation and the combustion has to be considered as complementary data. However, these data could be very helpful in a toxicological approach. The analytical part of that work was performed by using an Automatic Thermal Desorber linked to a coupled Gas Chromatograph - Mass Spectrometer (ATD-GC-MS). This is a methodology used in measurement of air pollution so it is a convenient tool for our purpose.

\section{METHODS AND MATERIAL}

\section{Site Description}

The experiment was carried out in South Corsica (France), it is a coastal region near Porto Vecchio town (see Fig. 1). In the past this area was frequently submitted to several dramatic wildfires, most of them occurred during the summer under western windy condition, high ambient temperature and drought conditions. The site was chosen by our public partners from the French Forest Service and Fire Brigade Service. Situated on an uneven terrain, the experimental plot was in the shape of a rectangle, 30 meters wide perpendicular to the slope with a north-western prospect on that side and 80 meters long parallel to the slope. A safety belt of 20 to 30 meters wide was build with a bulldozer. This buffer zone between the plot and the surrounding vegetation was necessary to prevent any fire escape (see Fig. 2).

The mean height of vegetation was estimated at 2-3 $\mathrm{m}$. The shrub layer represented most of the vegetation cover and the herbaceous layer was sparsely distributed on the parcel. Dominant species were olive tree (Olea europaea), strawberry tree (Arbutus unedo), white heath (Erica arborea), cistus (Cistus monspeliensis), golden-chain (Cytisus triflorus) and oak (Quercus ilex).

\section{Experimental devices}

Two sampling devices were used: smoke adsorption on Tenax and air collection in Tedlar bags.

Device 1: it consists of a portable air sampling pump linked to a pyrex cartridge filled with an adsorbent. The pump flow rate was $150 \mathrm{~mL} / \mathrm{mn}$. A gas volume $(2.25 \mathrm{~L})$ passes through the cartridge and the molecules present in the gas phase are trapped. The sampling zone was located at the end of the plot on the fuel break so as to analyze the atmosphere's composition 30 meters away from the fire zone, see Fig. 3. A thermocouple was used to measure the temperature during the sampling. The cartridges were rapidly brought to the laboratory and analyzed in order to avoid further oxidation. 


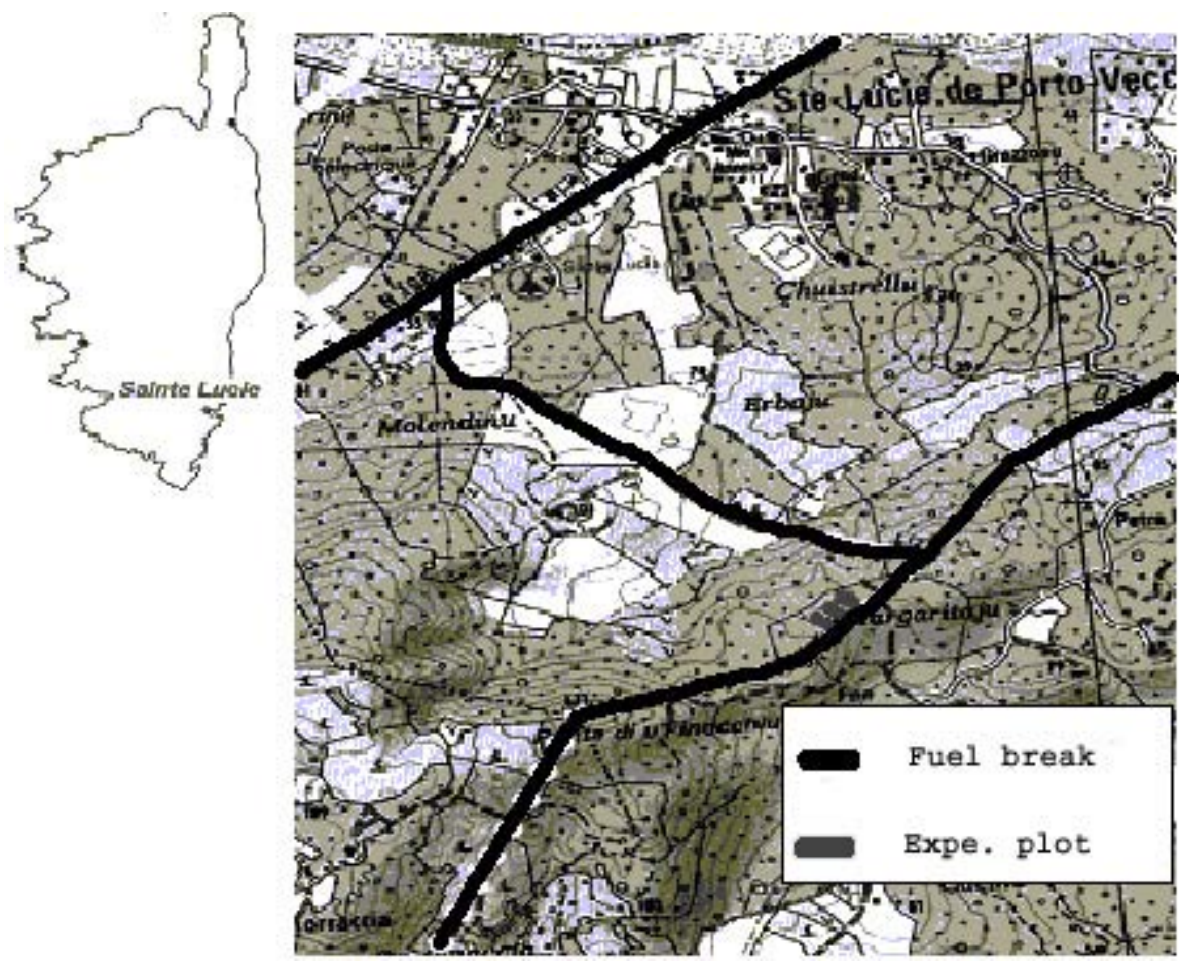

Fig. 1. Localization of the experimental plot.

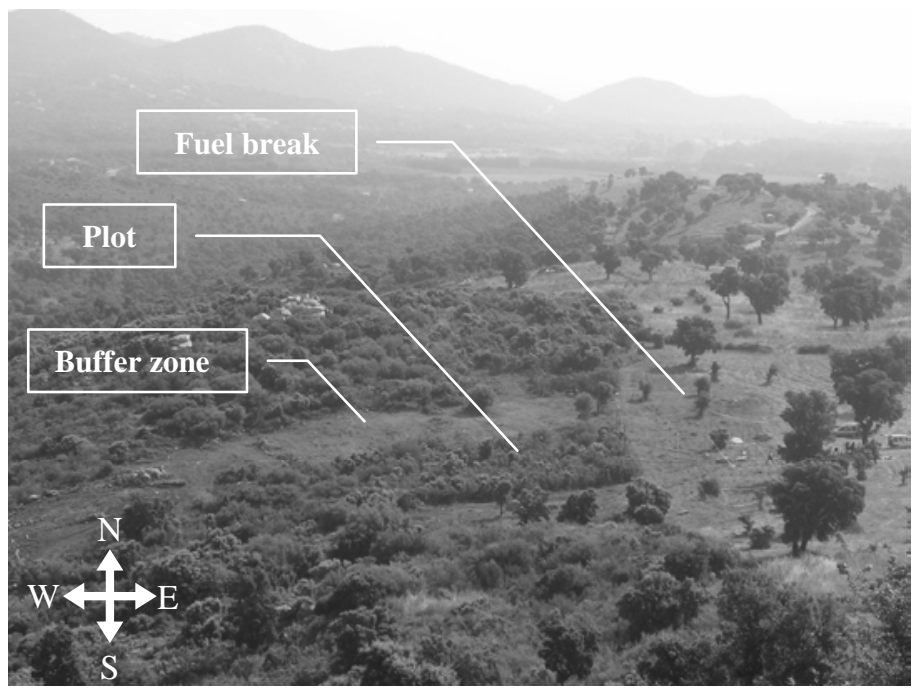

Fig. 2. View of the experimental plot. 
Device 2: it consists of a portable air sampling pump allowing to get a volume of $25 \mathrm{~L}$ on the top of the vegetation via a high temperature resistant tube (Teflon) into a Tedlar bag. The pump flow rate was $2.5 \mathrm{~L} / \mathrm{mn}$. Thanks to a thermocouple located in the sampling zone, we recorded the temperature in the vegetation. Two bags were successively used in order to determine the air composition at two different distances from the flame, see Fig. 3. Bag number 1 was filled until temperature reached $200^{\circ} \mathrm{C}$. Unfortunately, we did not fill bag number 2 because the temperature did not reach the value of $200^{\circ} \mathrm{C}$. The bag was brought to the laboratory and its content analyzed.

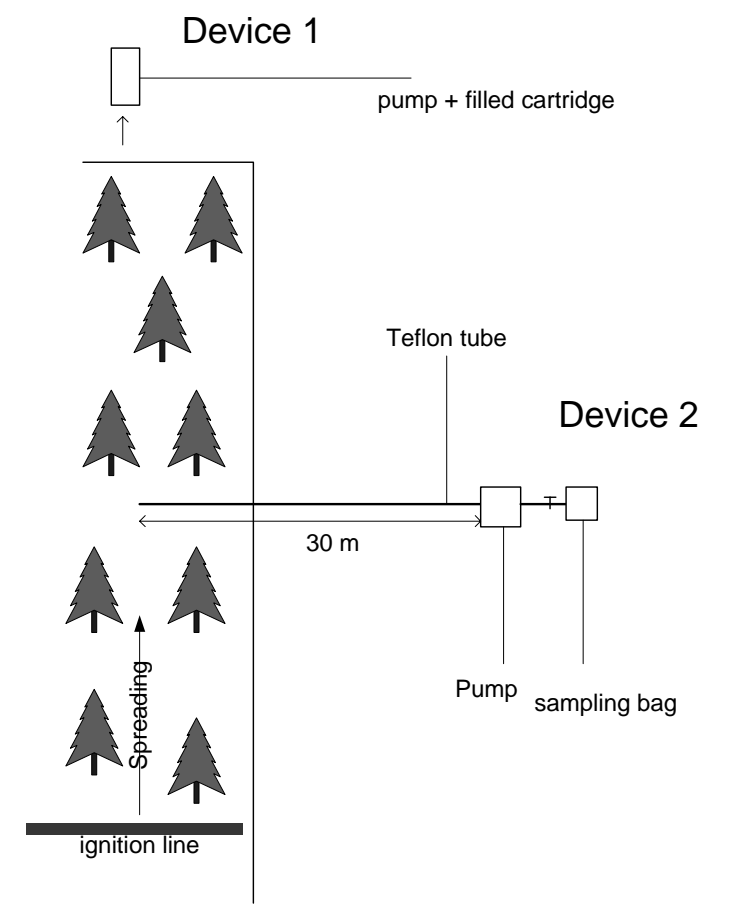

Fig. 3. Disposition of sampling devices on the plot.

\section{Analytical Conditions}

The analyses were carried out on July 04, 2004 at the laboratory after the experiment using an Automatic Thermal Desorber Perkin Elmer ${ }^{\circledR}$ ATD turbomatrix. A cartridge was brought to $280^{\circ} \mathrm{C}$ during 10 minutes and a carrier gas flushed the sample towards a cold trap at $5^{\circ} \mathrm{C}$. In a second step, the cold trap was programmed for an increase in temperature by 5 to $280^{\circ} \mathrm{C}$ at $40^{\circ} \mathrm{C} / \mathrm{s}$ then held an isotherm at $280^{\circ} \mathrm{C}$ during 3 minutes, the compounds were then desorbed to the chromatograph. The chromatograph and the mass spectrometer are Perkin Elmer ${ }^{\circledR}$ Clarus 500 apparatus. The carrier gas was helium which exerted a pressure of 20 psi at the head of the column. The chromatograph was equipped with a non-polar column (Rtx-1, dimethylsiloxan), length: 60 meters and internal diameter: $0.22 \mu \mathrm{m}$. This column was coupled with the mass detector equipped with a liner $0.75 \mathrm{~mm}$ in diameter. Detection was done by a quadripolar analyzer made up of an assembly of four parallel electrodes of cylindrical section. The temperature program of the analysis orders an increase in temperature from 50 to $260^{\circ} \mathrm{C}$ at $2^{\circ} \mathrm{C}$ per 
minute with a stage at $260^{\circ} \mathrm{C}$ during 10 minutes. The content of the Tedlar bag was analyzed using the same analytical conditions.

\section{RESULTS AND DISCUSSION}

On three samples with three cartridges we could identify the same 39 products in the smoke samples the most frequent are mainly benzenic and phenolic compounds, we present in Table 1 the list of molecules identified. The products are listed in their order of issue from the chromatographic column. They are characterized by their name, chemical formula and Chemical Abstract Service number.

Table 1. Compounds identified in the smoke.

\begin{tabular}{|c|c|c|c|c|}
\hline $\mathbf{N}^{\circ}$ & Name & $t_{r(\mathrm{mn})^{a}}$ & \begin{tabular}{|l} 
Formula \\
\end{tabular} & $\mathbf{N}^{\circ}$ CAS \\
\hline 1 & Acetone & 5.96 & $\mathrm{C}_{3} \mathrm{H}_{6} \mathrm{O}$ & $67-64-1$ \\
\hline 2 & Furan & 6.04 & $\mathrm{C}_{4} \mathrm{H}_{4} \mathrm{O}$ & $110-00-9$ \\
\hline 3 & Acetic acid, methylester & 6.29 & $\mathrm{C}_{3} \mathrm{H}_{6} \mathrm{O}_{2}$ & $79-20-9$ \\
\hline 4 & $\begin{array}{l}\text { Propanal,2-methyl- } \\
\end{array}$ & 6.58 & $\mathrm{C}_{4} \mathrm{H}_{8} \mathrm{O}$ & $78-84-2$ \\
\hline 5 & Methylvinylketone & 6.74 & $\mathrm{C}_{4} \mathrm{H}_{6} \mathrm{O}$ & $70-94-4$ \\
\hline 6 & Pentane,2-methyl- & 6.81 & $\mathrm{C}_{6} \mathrm{H}_{14}$ & $107-83-5$ \\
\hline 7 & 2,3-butanedione & 6.92 & $\mathrm{C}_{4} \mathrm{H}_{6} \mathrm{O}_{2}$ & $431-03-8$ \\
\hline 8 & Heptane & 7.33 & $\mathrm{C}_{7} \mathrm{H}_{16}$ & $142-82-5$ \\
\hline 9 & Acetic acid & 7.64 & $\mathrm{C}_{2} \mathrm{H}_{4} \mathrm{O}_{2}$ & $64-19-7$ \\
\hline 10 & Butanal,3-methyl & 8.42 & $\mathrm{C}_{5} \mathrm{H}_{6} \mathrm{O}$ & $590-86-3$ \\
\hline 11 & Benzene & 8.64 & $\mathrm{C}_{6} \mathrm{H}_{6}$ & $71-43-2$ \\
\hline 12 & Heptene & 9.78 & $\mathrm{C}_{7} \mathrm{H}_{14}$ & $592-76-7$ \\
\hline 13 & 1 H-pyrole,1-methyl & 11.29 & $\mathrm{C}_{5} \mathrm{H}_{7} \mathrm{~N}$ & $96-54-8$ \\
\hline 14 & $1 \mathrm{H}$-pyrole & 12.25 & $\mathrm{C}_{4} \mathrm{H}_{5} \mathrm{~N}$ & $109-97-7$ \\
\hline 15 & $\begin{array}{l}\text { Toluene } \\
\end{array}$ & 12.84 & $\mathrm{C}_{7} \mathrm{H}_{8}$ & $108-88-3$ \\
\hline 16 & Furfural & 16.24 & $\mathrm{C}_{5} \mathrm{H}_{4} \mathrm{O}_{2}$ & $98-01-1$ \\
\hline 17 & Ethylbenzene & 18.74 & $\mathrm{C}_{8} \mathrm{H}_{10}$ & $100-41-4$ \\
\hline $18+9$ & $\mathrm{~m}+\mathrm{p}$ Xylene & 19.34 & $\mathrm{C}_{8} \mathrm{H}_{10}$ & $106-42-3,108-38-3$ \\
\hline 20 & Styrene & 20.72 & $\mathrm{C}_{8} \mathrm{H}_{8}$ & $100-42-5$ \\
\hline 21 & o Xylene & 21.00 & $\mathrm{C}_{8} \mathrm{H}_{10}$ & $95-47-6$ \\
\hline 22 & Nonene & 21.55 & $\mathrm{C}_{9} \mathrm{H}_{19}$ & $124-11-8$ \\
\hline 23 & $\alpha$ Pinene & 24.76 & $\mathrm{C}_{10} \mathrm{H}_{16}$ & $80-56-8$ \\
\hline 24 & Furfural,5-methyl & 24.58 & $\mathrm{C}_{6} \mathrm{H}_{6} \mathrm{O}_{2}$ & $620-02-0$ \\
\hline 25 & Benzaldehyde & 25.90 & $\mathrm{C}_{7} \mathrm{H}_{6} \mathrm{O}$ & $100-52-7$ \\
\hline 26 & Benzonitrile & 26.98 & $\mathrm{C}_{7} \mathrm{H}_{5} \mathrm{~N}$ & $100-47-0$ \\
\hline 27 & Phenol & 28.63 & $\mathrm{C}_{6} \mathrm{H}_{6} \mathrm{O}$ & $108-95-2$ \\
\hline 28 & Benzofuran & 28.78 & $\mathrm{C}_{8} \mathrm{H}_{6} \mathrm{O}$ & $271-89-6$ \\
\hline 29 & Decene & 29.41 & $\mathrm{C}_{10} \mathrm{H}_{20}$ & 872-05-09 \\
\hline 30 & Indene & 32.54 & $\mathrm{C}_{9} \mathrm{H}_{8}$ & $95-13-6$ \\
\hline 31 & O. Cresol & 34.15 & $\mathrm{C}_{7} \mathrm{H}_{8} \mathrm{O}$ & $95-48-7$ \\
\hline 32 & P. Cresol & 35.88 & $\mathrm{C}_{7} \mathrm{H}_{8} \mathrm{O}$ & $106-44-5$ \\
\hline 33 & Phenol, 2-methoxy & 35.94 & $\mathrm{C}_{7} \mathrm{H}_{8} \mathrm{O}_{2}$ & $90-05-1$ \\
\hline 34 & Naphthalene & 43.30 & $\mathrm{C}_{10} \mathrm{H}_{8}$ & $91-20-3$ \\
\hline 35 & Phenol, 2-methoxy-4-methyl & 44.07 & $\mathrm{C}_{8} \mathrm{H}_{10} \mathrm{O}$ & $93-51-6$ \\
\hline 36 & Decanol & 45.10 & $\mathrm{C}_{10} \mathrm{H}_{22} \mathrm{O}$ & $112-30-1$ \\
\hline 37 & Phenol, 4-ethyl-2-methoxy & 50.42 & $\mathrm{C}_{9} \mathrm{H}_{12} \mathrm{O}_{2}$ & $2785-89-9$ \\
\hline 38 & 2-Methoxy-4-vinylphenol & 52.75 & $\mathrm{C}_{9} \mathrm{H}_{10} \mathrm{O}_{2}$ & $7786-61-0$ \\
\hline 39 & Phenol, 2,6-dimethoxy & 54.92 & $\mathrm{C}_{8} \mathrm{H}_{10} \mathrm{O}_{3}$ & $91-10-1$ \\
\hline
\end{tabular}

${ }^{\mathrm{a}} \mathrm{t}_{\mathrm{r}}$ is the retention time of a compound in the chromatographic column. 
Among these benzene-derived products and phenol-derived products, we could identify one terpenic molecule ( $\alpha$ pinene), one Polycyclic Aromatic hydrocarbon (naphthalene), 3 nitrogenized compounds and a few hydrocarbons. Except the BTX compounds, discussed hereafter, one notes that acetone, heptane, acetic acid, styrene, benzaldehyde, phenol and benzofuran are all mucous membrane and skin irritants $[7,8]$.

All the products present in the smoke have a toxicity depending on their concentrations. The Exposure Limit Value ELV (concentration limit in the air with an exposure time of $15 \mathrm{mn}$ ) and the Average Value of Exposure AVE (concentration limit in the air for an exposure time of 8 hours) are safety criteria that we used to classify the compounds. In terms of flammability, the compounds are classified according to the value of boiling point (the temperature at which the vapor of the liquid is in equilibrium with atmospheric pressure). The lower the boiling point, the greater the fire hazard. The flash point is an important criterion (the minimum temperature at which a liquid gives off vapor in sufficient concentration to form an ignitable mixture with air near the surface of the liquid). The lower is the flashpoint the greater is the fire hazard. Table 2 represents the physical characteristics of BTX compounds and Table 3 represents the toxicological characteristics of this compound [9].

We chose to quantify the BTX for two reasons: first, they are present in the 3 tubes at strong concentrations and second, they are very toxic. Indeed benzene is irritating and depressor of the central nervous system. Vapor inhalation involves giddiness, nauseas, confusions and irritation of respiratory tracts. It is carcinogenic and affects the osseous marrow in the long run. Toluene is a mucous membrane and skin irritant, in case of inhalation, risks of pneumopathy are possible. Psycho-syndrome is often related (tiredness, sleep disorder, memory loss...) in the long run. Xylene involves repeated vomiting, pulmonary oedema, neurological attack in the long run and nasal dryness, cough or bronchitis [9].

Table 2. Physical characteristics of BTX compounds.

\begin{tabular}{|l|l|l|}
\hline Products & Boiling point $\left({ }^{\circ} \mathbf{C}\right)$ & Flash point $\left({ }^{\circ} \mathbf{C}\right)$ \\
\hline Benzene & 80 & -11 \\
\hline Toluene & 130 & 4 \\
\hline Xylene & 140 & 30 \\
\hline
\end{tabular}

Table 3. Toxicological characteristics of BTX compounds.

\begin{tabular}{|l|l|l|l|l|}
\hline Products & Toxicity & Inflammability & AVE $\left(\mathbf{m g} / \mathbf{m}^{\mathbf{3}}\right)$ & $\mathbf{E L V ~}\left(\mathbf{m g} / \mathbf{m}^{\mathbf{3}}\right)$ \\
\hline Benzene & Raised & Raised & 16 & 30 \\
\hline Toluene & Means & Means & 375 & 550 \\
\hline Xylene & Means & Means & 435 & 650 \\
\hline
\end{tabular}

Figure 4 shows the reconstituted chromatogram of a sample (only the previous cited compounds are mentioned: $\mathrm{B}$ for benzene, $\mathrm{T}$ for toluene, oX for ortho-xylene $\mathrm{pX}$ for para-xylene and $\mathrm{mX}$ for meta-xylene). 
The sample collected in the tedlar bag was also analyzed, we found a similar composition as that in the cartridge. A difference was expected but the fire spread was very slow and the wind drove the smoke to the sampling zone.

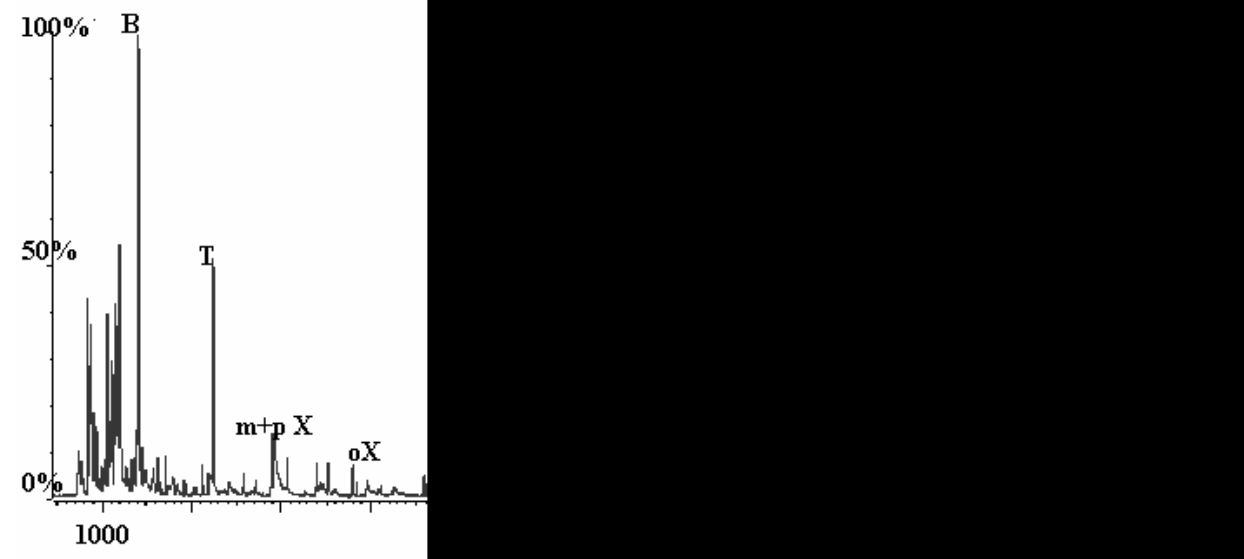

Fig. 4. Reconstructed chromatogram of a smoke sample.

Figure 5 represents a mixture of BTX standards. The method of quantification is based on the external calibration line, for that we prepared mixtures of BTX standards with various concentrations. Commercial BTX mixture are supplied with $100 \mu \mathrm{g} / \mathrm{mL}$ of each product in methyl alcohol. Standards were quantitatively deposed in cartridges and analysed with the chromatographic conditions described above. The mass spectrometer is not able to detect separately meta-xylene and para-xylene so, the quantification of xylene refers to the total concentration (ortho-, para- and meta- isomers) in the smoke.

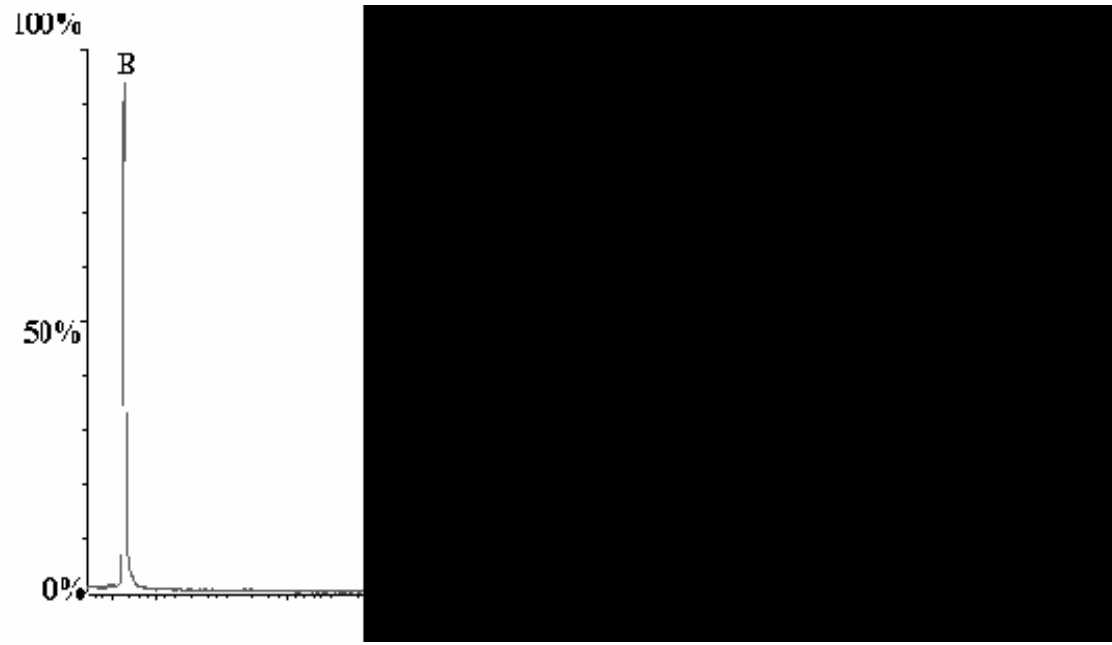

Fig. 5. Reconstructed chromatogram of a standard mixture of BTX in methanol. 
Table 4 represents the concentration of BTX in the volume of smoke sampled. The deviation corresponds to the variations with the various concentrations present in the three cartridges filled with Tenax.

Table 4. Concentrations of the BTX compounds.

\begin{tabular}{|l|l|l|}
\hline Product & Concentration $\mathbf{( m g / \mathbf { m } ^ { 3 } )}$ & Deviation (\%) \\
\hline Benzene & 28 & 0.21 \\
\hline Toluene & 15 & 0.11 \\
\hline Xylene $\left(\mathrm{m}+\mathrm{o}^{+} \mathrm{p}\right)$ & 47 & 0.31 \\
\hline
\end{tabular}

The results show a raised content of benzene in the samples of smoke, the concentration was equal to the ELV for this compound. On the other hand, concentration values of toluene and xylene were quite lower than the ELV of those compounds. The content values were very similar in the three samples as shown by the deviation in Table 3 . These preliminary results indicate that firefighters are exposed to a toxic environment on wildland fires. Such studies should be multiplied in order to verify the presence of carcinogenic compounds in smokes from fires of vegetation. In the long run, in addition to fine particles, these compounds are dangerous not only for the firemen's health but also ecology with the contamination of soil and water.

\section{CONCLUSION}

This first experiment allowed us to analyze the composition of smoke produced in a wildland fire. Trapping molecules in the smoke with tenax is easy and gives reproducible data as shown in the analysis. Qualitative and quantitative measurement are possible with the ATD-GC-MS technique. Smoke released in a fire of Mediterranean scrub is characterized by two dominant classes of compounds: derivatives of benzene and derivatives of phenol.

The benzene content exceeds the threshold value (ELV), toluene and xylene contents remain quite lower than the threshold value. Such a study could be the first step in a respiratory protection program to protect firefighters from respiratory hazards. Considering that the contamination of soil an water supplied by these chemical agents from wildland fires present a high potential risk, an other application could be found in ecological assessment and environmental safety.

The sampling with tedlar bags was not conclusive, it will be necessary thereafter to take atmosphere samples at various heights in the vegetation (in order to catch Volatil Organic Compounds, reaction intermediates and smoke separately). This original device will be used in controllable conditions in intermediary scaled experiments developed in the laboratory. In easier conditions without slope and wind, important results are expected. Then we'll give a chemical entry: composition of the gas phase, for modeling purposes.

This kind of work requires right weather conditions thus the number of experiments is limited. However, an other experiment was carried out recently on an homogeneous medium. The fire was spreading over broom and samples of smoke were sampled thanks to the device 1 . Preliminary analyses showed a smoke composition very similar to the results presented in this paper. Especially high content of Benzene and Xylene were detected. 


\section{REFERENCES}

[1] Simeoni, A., Santoni, P.A., Bosseur, F., Rossi, J.L., Morandini, F., Silvani, X., Balbi, J.H., Leoni, E., Marcelli, T., Rossi, L., Cancellieri, D., Barboni, T., Rinieri, F., and Innocenti, E., "Wind and Vegetation Effects on the Dynamic of a Fire Spreading Across an Heterogeneous Mediterranean Shrub," Submitted to the 8th International Symposium on Fire Safety Science, 2005.

[2] Kifani-Sahban, F., Belkbir, L., and Zoulalian, A., "Study of the Slow Pyrolysis of Moroccan Eucalyptus by Thermal Analysis," Thermochimica Acta, 284, pp 341-349, (1995).

[3] Raimo, A., Kuoppala, E., and Oesch, P., "Formation of the Main Degradation Compound Groups from Wood and its Components During Pyrolysis,” Journal of Analytical and Applied Pyrolysis, 36, pp. 137-148, (1996).

[4] Leoni, E., "Modélisation Dynamique des Systèmes Thermochimiques: Réactions en Phase Liquide-dégradation Thermique d'un Combustible,” Ph-D Thesis, University of Corsica, Corte, 2002, 171p.

[5] Faix, O., Meier, D., and Fortman, I., "Degradation Products of Wood, Gas Chromatographic Separation and Mass Spectrometric Characterization of Monomeric Lignin Derived Products," Holz als Roh-und Werkstoff, 48, pp. 281285, (1990).

[6] Faix, O., Fortman, I., Bremer, J., and Meier, D., "Thermal Degradation Products of Wood, Gas Chromatographic Separation and Mass Spectrometric Characterization of Polysaccharide Derived Products," Holz als Roh-und Werkstoff, 49, pp. 213-219, (1991).

[7] Bernier, S., Diers, B., Freyria, A.M., Karli, M., Picot, A., and Vaganay, E., 100 Fiches Pratiques, Sécurité des Produits Chimiques au Laboratoire, Dunod, Paris, 2001, p. 223.

[8] Bernier, S., Aubert, M.H., Boisset, M., Brendel, A., Diers, B., Freyria, A.M., Munch, S., and Vaganay, E., 100 Nouvelles Fiches, Sécurité des Produits Chimiques au Laboratoire, Dunod, Paris, 2004, p. 231.

[9] Margossian, N., Risque Chimique, Dunod, Paris, 2002, p. 232. 
